\title{
Impulsive noise in images: a brief review
}

\author{
Alenrex Maity* and Rishav Chatterjee \\ School of Computer Science Engineering, KIIT University, Odisha, India
}

\section{(C2018 ACCENTS}

\begin{abstract}
Noise is introduced when capturing the image or transmitting the image. Noise means random variation of intensity level. Some additional information is added to the pixels and makes the noisy image. The pixel which is shown in the image is not the correct pixel some extraneous value is added to the true pixel value it degrades the quality of the image it also degrades the ability of the human observation of some diagnostic problem. There are many factors to introduce the noise in the image. Generally noise is of two types' additive noise and multiplicative nose. Some other classifications are available through the image processing filed such as additive, multiplicative and impulse (random) noise. Impulse noise is one the type of noise which modifies the pixel values randomly. This type of noise can be classified into two categories such as static and dynamic (random). This paper deals with the performance analysis of various filtering technique which is to remove/reduce the impulse noise from the image. The performances metric are like MSE, SNR, and PSNR etc.
\end{abstract}

\section{Keywords}

Impulse noise, Filtering, MSE, PSNR.

\section{Introduction}

Image is the graphical representation of some object in any particular time instance. Image is again classified into various categories as follows (Figure 1).

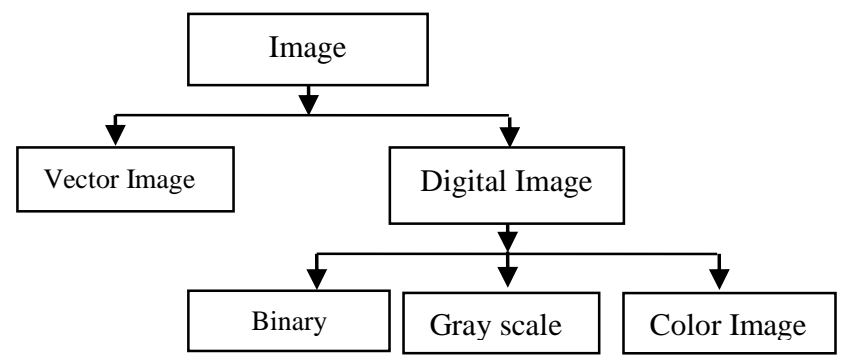

Figure 1 Classification of images

In digital signal processing image is represented in co-ordinate format or matrix format, where 2D array represent the image. In each cell the data is known as the pixel values. Each pixel represents the intensity value of brightness individually. Together all intensity value consist the total image. Image is valuable information in many scenarios. According to the values present in the pixels image is classified. In case of binary image the pixel values only represents 0 or 1 , in gray scale image the pixel value varies from 0 to 255 , in colour image intensity values varies from 0 to 255 for each colour i.e. red, green, blue.

6

\footnotetext{
*Author for correspondence
}

Noise means random variation of intensity level. Some additional information is added to the pixels and makes the noisy image. The pixel which is shown in the image is not the correct pixel some extraneous value is added to the true pixel value. Mathematically noise is classified into two basic models i) additive and ii) multiplicative. Additive noise is easy to model and it can be reduced or removed easily. It is independent of signal. Mathematically, it is described as

$t(p, q)=o(p, q)+n(p, q)$

Whereas multiplicative noise is complex to model and it is difficult to reduce or remove. It is signal dependent. Mathematically, it is described as

$t(p, q)=o(p, q) * n(p, q)$

Where, $t$ is the observed image with noise, and $o$ is the true signal (image), and $\mathrm{n}$ is the noise component. Some other classifications [1, 2] are available through the image processing filed such as additive, multiplicative and impulse (random) noise. Impulse noise is the one type of noise which randomly modifies the pixel values. This type of noise can be classified into static and dynamic (random) (Figure 2). 


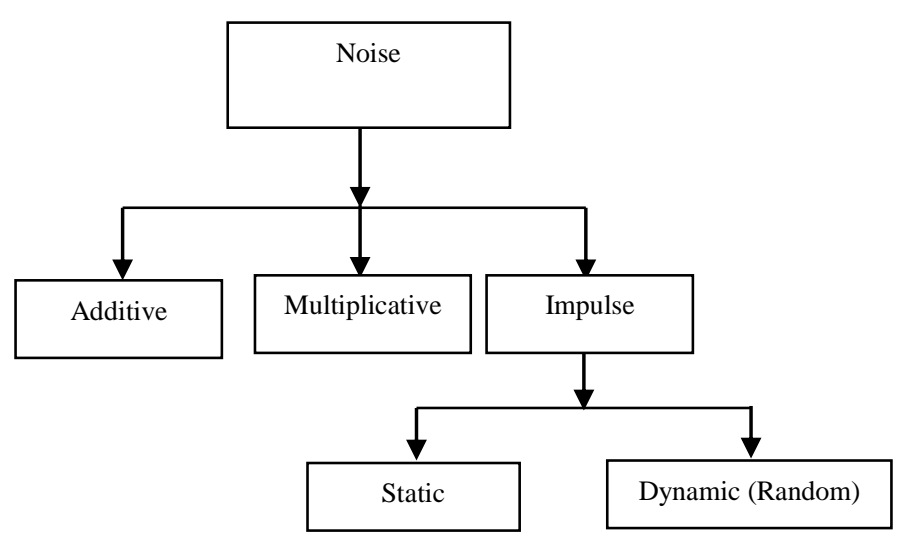

Figure 2 Types of noise

Following are the basic factors for noise in image

- Environmental conditions

- Temperature of the sensor

- Confliction in the transmission channel

- Insufficient light

- Dust on the screen during scanning the image

Noise in image is one of the vital issues which degrade its value in all aspect. It degrades the image quality. It also hides some important details of image which creates the problem for the further processing like's segmentation, edge detection etc. It also decreases the ability of the human observation to diagnosis object. So removing the noise from the image is an essential step in image processing to get the better quality of image. Noise reduction is a process which restores the image from the noisy image with better quality.

Recovery of image follows two step processes one is detection the noise and then reduction mechanism applied on it. Impulse noise is more of general kind of noise where the noise occurs during image acquisition and transmission. During email compression also the impulse noise generates because of degrading the quality of the image the pixel values get modified and hence the noise arises. Impulse noise can be classified into two categories. One is random valued impulse noise (RIVN) ad other one is salt \& pepper impulse noise (SPIN).

In this paper we have elaborated the basic concept of Impulse noise, specifically salt and pepper noise and reduction mechanism to reduce the salt \& pepper noise and a comparative analysis with filtering techniques that have been implemented through the years.

\section{Material and methods}

\subsection{Impulse noise}

Impulse noise $[1,3,4]$ is the noise arises in image due to signal miss transmission. It is otherwise known as spike noise or independent noise. In this type of noise in pixel values get modified independently. According to the nature of modification impulse noise is classified to static or dynamic type. We consider $\mathrm{O}$ is the original image and $\mathrm{T}$ is the noisy image. Mathematically impulse noise can be described by two equations which are discussed below. First model follows the additive noise model where $\mathrm{T}$ is defined as:

$$
\begin{aligned}
& T(x, y)= \\
& \left\{\begin{array}{c}
o(x, y): \text { withprobability } 1-p \\
o(x, y)+n(x, y): \text { withprobabilityp }
\end{array}\right.
\end{aligned}
$$

In this equation, noise density is represented by $\mathrm{P}$ (i.e. $0 \leq \mathrm{P} \leq 1$ ). If the value of $\mathrm{P}$ is high means higher corruption level. Another model uses a simplified version of above equation. For model, $\mathrm{T}$ is defined as:

$T(x, y)=\left\{\begin{array}{c}o(x, y): \text { withprobability } 1-p \\ n(x, y): \text { withprobabilityp }\end{array}\right.$

In the second kind of impulse noise the pixel is directly replaced with noisy values. As from the above two equations it's clear that we can't say impulse noise is either additive or multiplicative in nature. It's more of some different category, that's why we classify it as another category called impulse noise the (3) equation defines the noise value as variant and the (4) equation says its static in nature. So it's classified into two types one is random and other is salt \& pepper.

In dynamic type the pixel values get modified independently as well as randomly, that's why it's known as random valued impulse noise (RVIN). In case of static impulse noise its pixel values get modified by only two values, either high or low value of the range.

In generally pixels represents the intensity values ranging from low to high. For gray scale image the pixel values ranging from 0 to 255 are the possibilities. Where 0 represent the lowest intensity value and 255 represent the highest intensity value. That means from black (0) to white (255). In static impulse noise the original value of the pixel get modified by either black or white. In generally dark part of the image get modified by the white pixel and vice versa. 
That's why it is known as salt (white) and pepper (black) noise. This type of noise is a kind of general noise which occurs because of image compression, signal miss transmission, presence of dust particle at the time of image acquisition. A standard gray scale image is consisting of intensity value from the weak to the strong excluding 0 and 255 . Between the years many researchers implemented their research on image processing taking some standard images such as barbara.png, boat.png, house.png, lena.png, peppers.png (Figure 3).

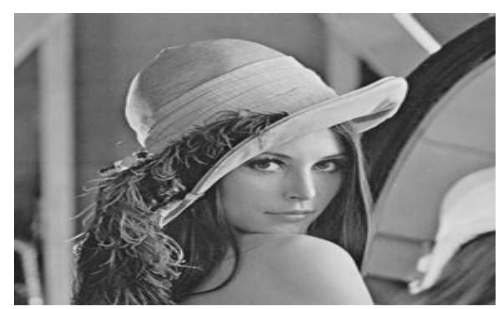

(a)Lena

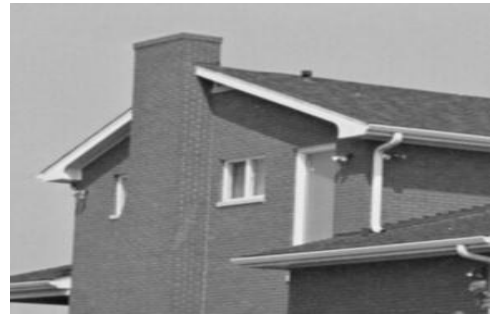

(d) House

Figure 3 All the standard images

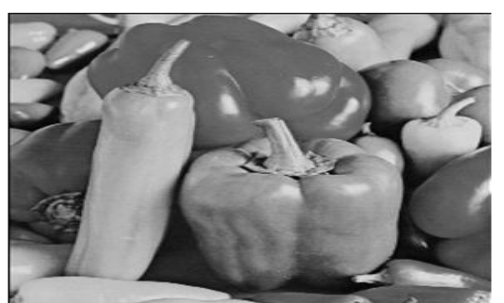

(b) Peppers

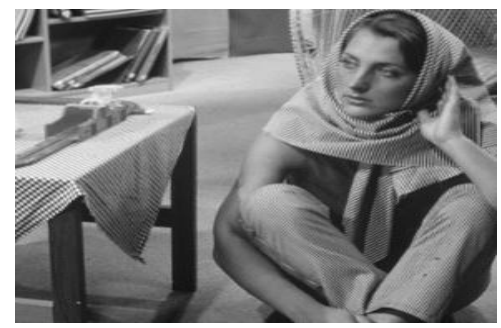

(e) Barbara

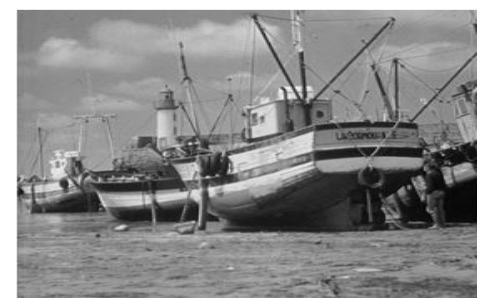

(c) Boat

Static impulse noise is the common type of impulse noise. It is very easy to find as in this kind of noise digital image is affected by two kinds of intensity values i.e. either weak (0) or strong (255).

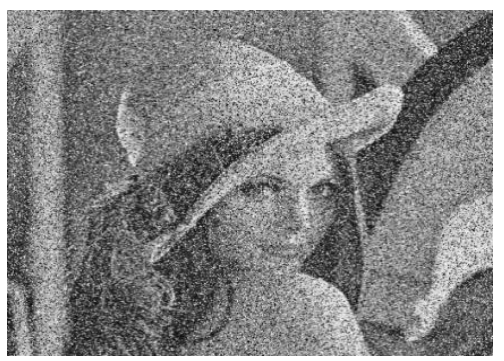

(a)Lena

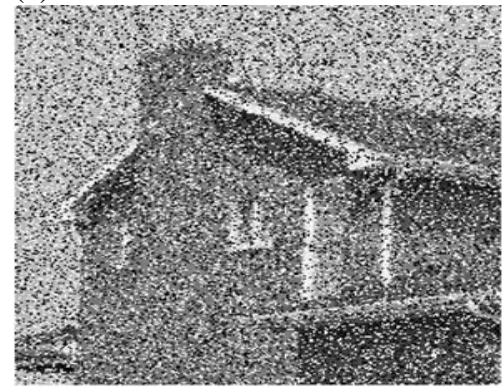

(d) House

\section{Figure 4 All}

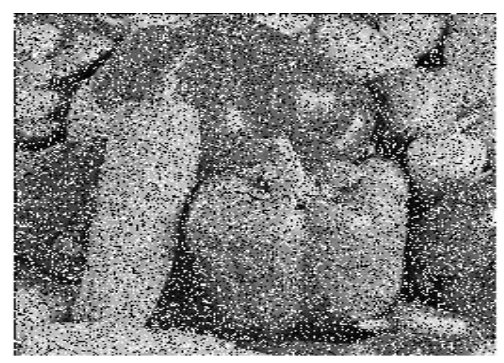

It is uniform in nature means if we take a window from the image then we will find almost similar density of 0 and 255 forming pepper and salt. So it is called as salt and pepper noise (Figure 4).

(b) Peppers

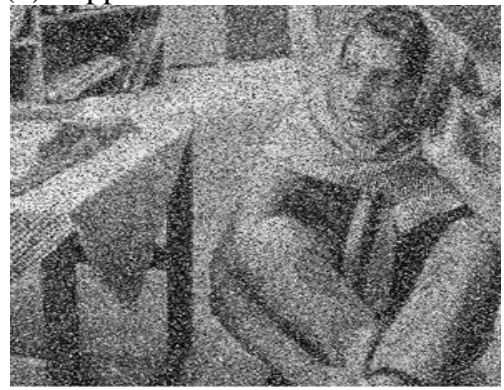

(e) Barbara

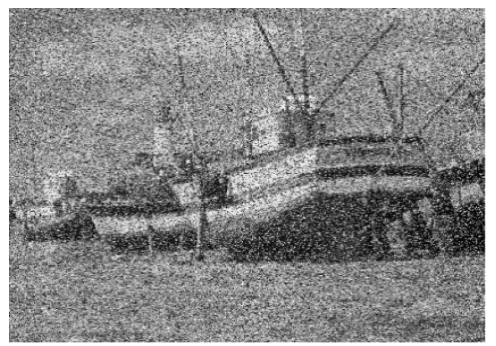

(c) Boat 
Causes of salt \& pepper

- Bit Error in image

- Sudden disturbance in image signal

- during image compression

- Dust particle in sensor.

\section{Literature survey}

Original Image is always required for any kind of analysis in image processing. It is very much essential to preserve the original image. In general images get corrupted during image acquisition and transmission due to noisy channel, dust particle in sensor and many more. Many recovering tools and techniques being evolved during image through the years. Mainly different filtering techniques are implemented in various domains. Filtering techniques are dividing into different categories such as spatial domain, transform domain. For Impulse noise reduction filtering technique fall into two categories linear filtering and non-linear filtering (Figure 5).

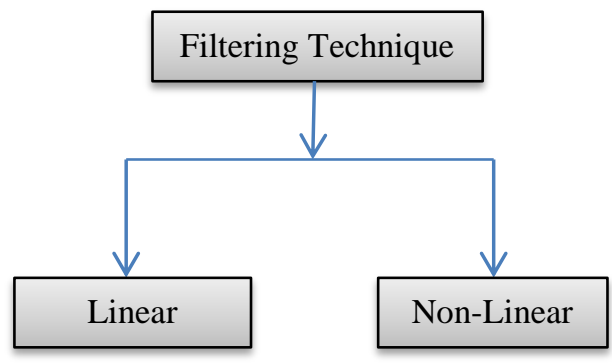

Figure 5 Types of filtering

Linear filtering [3] is the Technique where the filtering technique is implemented over all the pixels of image whether the pixel is corrupted or not. Linear filtering techniques are the simplest techniques where the mechanism is applied to all the pixels linearly without check for the corruption. These techniques are very easy to understand implement as compare to non-linear ones. Median and mean based filters are the most common type linear filters.

\section{1linear filtering}

\subsubsection{Mean filter}

Mean filter also known as average filter. It is a linear filter. Mean filter reduces the noise from the image by using the square window $(3 \times 3,5 \times 5$, and $7 \times 7)$ of grey level. In mean filter take the noisy pixel in the centre of the square window then calculated the surrounding pixel of the centre pixel and the average value of the all pixels within the windows then the centre noisy pixel value is replace by the average value [5-9]. In mean filter each pixel value is replaced by the mean (average) value of its neighbours within the window including itself.

There are two main problems of mean filter

1. Each pixel is replaced by the average value of its surrounding pixels within the windows that means the pixel which is not noisy it also replaced by the average value.

2. When the filter neighbourhood straddles an edge, it will interpolate a new value for pixels on the edges and blur that edge. This is the problem when require the sharp edges as output.

\subsubsection{Median filter}

This filter is used for de-noising the image. It is like the mean filter but it is better than the mean filtering due to preserve the useful details of the image [10]. The median filter considers each pixel in the image in turn and looks at its nearby neighbors to decide whether or not it is representative of its surroundings. In median filter the noisy pixel is replaced by the median of the neighboring pixel values. Median filter $[1,3,11]$ best suit filtering technique for Salt \& pepper impulse noise in case of up to $40 \%$ noisy image. It is more over similar to mean filter. But it preserves the image details more efficiently than that of mean filter. In case of median filter [2].

\subsubsection{Weighted mean filter}

This is a modified version of basic mean filter, linear in nature. In this technique the product of weight [2] value and the pixel value is first calculated then their mean is calculated to be used in restoration of the noisy pixel. Where the weight is calculated in various ways. Most common way is the distance from the center noisy pixel of a window. In general the noisy center is given high weight. Concept is as given as in the Table 1.

Table 1 Weight matrix

\begin{tabular}{lllll}
\hline 1 & 1 & 1 & 1 & 1 \\
1 & 2 & 2 & 2 & 1 \\
1 & 2 & 3 & 2 & 1 \\
1 & 2 & 2 & 2 & 1 \\
1 & 1 & 1 & 1 & 1 \\
\hline
\end{tabular}

In this case the centre pixel is weighted as 3 whereas all the other pixels are assigned as per the distance from the centre.

3.1.4Trimmed mean filter

Modified version of mean filter. This filter has one more extra parameter called trimmed value. In this filter noisy pixel is replaced by the trimmed mean value. This gives more accuracy than that of mean and weighted mean. A trimming value [2] is first calculated then the window value having center pixel noisy is arranged in increasing order. Then according 
to trimming value $\mathrm{T}$ the sorted array is trimmed from both the side. Then mean value is calculated, by default trimming value is taken as 3 .

\subsubsection{Trimmed weighted mean filter}

This is the higher version of weighted and trimmed mean filter In this case in first step weight is calculated then trimming is done.

3.1.6Weighted median, trimming median, trimming weighted median filter

These filters $[2,10]$ are the similar to the modified mean filters. These are linear in nature. In this case median is calculated at the end instead of mean. These filters give more accurate result as compare to classical median filter.

3.1.7Non-linear filtering

Non-linear filtering [2, 12, 13] is more complicated but effective filtering methodology, which consist of two phases. In first phase detection of noisy pixel is take place and then in second phase reduction technique is implemented over the noisy pixel. It gives better result than that of linear once. In nonlinear filtering it preserves the edges more and less blurring effect.

\subsubsection{Adoptive median filtering}

In adoptive median filtering $[2,14,13]$ first detect the noisy pixels then taking that nosy pixel at the centre of the $3 \mathrm{X} 3$ window then median value is replaced. In this technique first step gives to check the median value is lies between the highest and lowest value in the window. In first step it checks for residual impulse value. If there are no impulses then it goes for the second level where it check for the centre pixel to be noisy. If the centre pixel is not corrupted then value remains unchanged, otherwise adoptive median filter (AMF) [13] value is replaced. If In the first step we found the impulses then simply increase the window size.

Many researchers through the years implemented many non-linear filtering algorithms to reduce salt and pepper impulse noise (SPIN) using spatial domain filtering which includes traditional methods, fuzzy logic [15], soft computing etc. Some filtering techniques with their characteristics and their advantages are given in following section.

\section{Evolution through the years}

Chen and $\mathrm{Wu}$ [3] in 2001 implemented an adoptive non-linear technique where the centre pixel is assigned with some weight it's basically a detection based algorithm which works more efficiently with average noise density. In 2005 AMF is implemented by chan et al.[14] which is basically a window based technique consisting of two phases first phase is noise detection then after the detection reduction is take placed with some objective function, this technique helps in preserving edges. In 2008 an modified version of mean filter was implemented by Kaisar and Mahmud named tolerance based selective arithmetic mean filtering technique (TSAMFT)[16].This technique is better than mean filter which helps in edge preserving as well as less blurring in this technique a tolerance value is implemented to protect the original pixel from destroying. Al-Khaffaf et al. [17] in 2008 proposed another technique TrackAndMayDel procedure (TAMD) which is based on Based on kFill algorithm which works on black and white fill sub iteration. It performs better result than that of Kfill algorithm. Gebreyohannes and Kim[18] in 2011 proposed a new gradient based three phase technique called as mean absolute gradient(MAG), in which phase one detect the noisy pixel, phase two helps in reduction, then finally using gradient technique image quality is enhanced .Basically this technique is more efficient to produce better quality image at the final step. Researchers also implemented fuzzy [19] based techniques in 2011. Turkmen implemented a technique of neuro-fuzzy inference system [4]. In this method corrupted pixels are detected by ANFIS then the Median filtering is performed for only these pixels. This technique gives better result in high noise density. Hsu et al. implemented cellular automata image denoising (CAID) toolkit [20]. It first detect the noisy pixels and replace them by the some rule of the automata gives more better result than median filter. Bansal and Kaushik used a adaptive fuzzy switching median filter [21] in 2011 which is a hybrid of simple adaptive median filter and fuzzy switching median filter to give a better image in highly noisy image. In the same year Babu et al. [22] used a modified median filtering where the noisy pixel is modified by a dynamic range of values, which is better than median filter, DBA, AMF in performance testing. Siddavatam et al. [23] in 2011 implemented an intelligent recursive algorithm (IRA). It is developed using PSM and median based filters, which remove noise much better with less computation time.

A histogram[19] based reduction methodology is implemented using fuzzy logic with adoptive filtering by Kaur in 2012 which Performs optimize result. In 2013 González-Hidalgo et al. implemented a fuzzy mathematical morphology technique where detection is done by fuzzy top-hat transforms \& reduction by T-norm[12] and mathematical morphing produce better result than that of DBA, SMF3, SMF5, AMF9, 
AMF17 [12]. Narayanan et al. [10] implemented trimmed median filter (TMF) [10] which is iteration based adoptive trimmed median filtering along with adoptive window trimmed filtering. It provides better result than that of AWMF. Neuro-fuzzy (NF) network based impulse noise filtering algorithm is implemented by $\mathrm{Li}$ et al. [24] in 2013 where combining two NF filters with a postprocessor. Each NF filter is a first order Sugeno type fuzzy inference system with 4-inputs and 1-output and evaluates a different relation between the median value of all the pixels in a predefined selecting data window and the three appropriate pixels in a filtering window. In 2013 another fuzzy filtering technique was implemented where the pixel with maximum membership degree will be selected and replaced by the noisy pixel by Mahallati et al. [11]. In 2014 Iterative unsymmetrical trimmed midpoint-median filter was proposed by Kumar and Abhilasha [25]. It gives better performance than modified decision based unsymmetrical trimmed median filter [25]. Singh and Prakash proposed modified adaptive median filters which first identify the presence of impulse noise then adaptive window filtering concept is used to filter the salt \& pepper noise [13]. Bai et al. [26] in 2014 proposed a continued fractions interpolation filter (CFIF), where noise free pixels are left unchanged, then, the weighted mean of four-direction continued fractions interpolation is computed to estimate the corrupted pixel value. Kayhan[27] in 2014 proposed a 2-stage impulse noise removal system where first, a neuro-fuzzy based impulse noise detector (NFIDET) is introduced to identify the noisy pixels. second An adaptive robust weighted mean (ARWM) filter removes a detected noisy pixel by adaptively determining filtering window size and replacing a noisy pixel with the weighted mean of the noise-free pixels in its window.

Fuzzy-cellular automata based filtering was proposed by Sahin et al. [28] in 2014 which reduces noise up to $85 \%$ where The algorithm describes a local fuzzy transition rule which gives a membership value to the corrupted pixel neighborhood and assigns next state value as a central pixel value. In present year iterative method for salt and pepper noise removal technique is proposed by Banerjee et al. [29]. The proposed method follows three steps first dived the image into four equal segments, then cross the middle and different pixel approximation (averaging) method is applied for each segments. Then above method is iterated a number of times till desired performance is achieved. Proposed method is successful in achieving accountable value of result for $40 \%$ to $80 \%$ level of noise Shown in Table 2.

Table 2 Different proposed algorithms for reduction of salt and pepper noise over the years

\begin{tabular}{|c|c|c|c|c|}
\hline & Author & Method & Characteristic & Advantage \\
\hline 2001 & $\begin{array}{l}\text { Tao Chen and Hong } \\
\text { Ren Wu }\end{array}$ & $\begin{array}{ll}\text { Centre } & \text { weighted } \\
\text { median filter. }\end{array}$ & $\begin{array}{l}\text { Median filter having centre value } \\
\text { some weight. }\end{array}$ & $\begin{array}{l}\text { It's a detection based } \\
\text { mechanism. }\end{array}$ \\
\hline 2005 & $\begin{array}{l}\text { Raymond H. Chan, } \\
\text { Chung-Wa Ho, and } \\
\text { Mila Nikolova }\end{array}$ & Adaptive median filter. & $\begin{array}{l}\text { Two state } \\
\text { 1-noise are detected by AMF } \\
2-\text { reduction is done by using } \\
\text { objective function }\end{array}$ & $\begin{array}{l}\text { Detection is possible and } \\
\text { Edge preserving. }\end{array}$ \\
\hline 2008 & $\begin{array}{lr}\text { Shahriar } & \text { Kaisar } \\
\text { Md.Sakib } & \text { Rijwan } \\
\text { Jubayer Al } & \text { Mahmud } \\
\text { Muhammad } & \text { Mizanur } \\
\text { Rahman } & \end{array}$ & $\begin{array}{lr}\text { Tolerance } & \text { Based } \\
\text { Selective } & \text { Arithmetic } \\
\text { Mean } & \text { Filtering } \\
\text { Technique } & \text { (TSAMFT) }\end{array}$ & $\begin{array}{l}\text { Using a threshold value called as } \\
\text { tolerance value to avoid destroying } \\
\text { the original pixel. }\end{array}$ & $\begin{array}{l}\text { Better than mean filter, edge } \\
\text { preserving, less blurring. }\end{array}$ \\
\hline 2008 & $\begin{array}{l}\text { H. S. M. Al-Khaffaf1, } \\
\text { Abdullah Z. Talib, } \\
\text { Rosalina Abdul Salam }\end{array}$ & $\begin{array}{l}\text { TrackAndMayDel } \\
\text { procedure } \\
\text { (TAMD) }\end{array}$ & $\begin{array}{l}\text { Based on kFill algorithm. works } \\
\text { black and white fill sub iteration. }\end{array}$ & Better than kFill algorithm. \\
\hline 2011 & $\begin{array}{l}\text { Tina Gebreyohannes } \\
\text { and Dong-Yoon Kim }\end{array}$ & $\begin{array}{l}\text { Mean Absolute } \\
\text { Gradient (MAG) }\end{array}$ & $\begin{array}{l}3 \text { phase } \\
\text { 1- Detection the noise } \\
\text { 2-Noise reduction } \\
\text { 3- Image Enhancement }\end{array}$ & $\begin{array}{l}\text { Remove salt and pepper } \\
\text { noise with high density and } \\
\text { produce better quality of } \\
\text { images. }\end{array}$ \\
\hline 2011 & $\begin{array}{l}\text { Chih-Yu Hsu , Ta-Shan } \\
\text { Tsui, Shyr-Shen Yu, and } \\
\text { Kuo-Kun Tseng }\end{array}$ & $\begin{array}{l}\text { Cellular Automata } \\
\text { Image } \quad \text { Denoising } \\
\text { (CAID) toolkit. }\end{array}$ & $\begin{array}{l}\text { First detect the noisy pixels and } \\
\text { replace them by the some rule. }\end{array}$ & Better than the median filter. \\
\hline 2011 & $\begin{array}{l}\text { Tina Gebreyohannes, } \\
\text { Dong-Yoon Kim }\end{array}$ & $\begin{array}{l}\text { MAG and Directed } \\
\text { filtering }\end{array}$ & $\begin{array}{l}\text { Two phase, First through MAG } \\
\text { detects the noise then remove the } \\
\text { noise through directional filtering. }\end{array}$ & $\begin{array}{l}\text { Better than DBA, AMF, } \\
\text { CBA filters. }\end{array}$ \\
\hline 2011 & K.Ratna Babu, L.Arun & Modified & Modify the corrupt pixel by & Better than Median Filter, DBA, \\
\hline
\end{tabular}




\begin{tabular}{|c|c|c|c|c|}
\hline & Author & Method & Characteristic & Advantage \\
\hline & Rahul, P.Vineet Souri & Filtering & dynamic range of values. & AMF, preserves edges. \\
\hline 2011 & $\begin{array}{l}\text { Harish Kumar Bansal, } \\
\text { Geeta Kaushik }\end{array}$ & $\begin{array}{l}\text { Adaptive } \\
\text { Switching } \\
\text { Filter }\end{array}$ & $\begin{array}{l}\text { Hybrid of simple adaptive median } \\
\text { filter and fuzzy switching median } \\
\text { filter. }\end{array}$ & $\begin{array}{l}\text { Reduce high density of } \\
\text { impulse noise. }\end{array}$ \\
\hline 2011 & $\begin{array}{l}\text { Rajesh Siddavatam, } \\
\text { Anshul Sood, Syamala } \\
\text { Jayasree P, and S P } \\
\text { Ghrera }\end{array}$ & $\begin{array}{l}\text { Intelligent Recursive } \\
\text { Algorithm (IRA) }\end{array}$ & $\begin{array}{l}\text { In this algorithm no threshold is } \\
\text { required. } \\
\text { It is developed using PSM } \\
\text { and median based filters. }\end{array}$ & $\begin{array}{l}\text { Remove noise much better } \\
\text { with less computation time. }\end{array}$ \\
\hline 2011 & Ilke Turkmen & $\begin{array}{lr}\text { adaptive } & \text { neuro-fuzzy } \\
\text { inference } & \text { system } \\
\text { (ANFIS) } & \end{array}$ & $\begin{array}{l}\text { Noisy pixels are detected by } \\
\text { ANFIS then median filter is used } \\
\text { for only noisy pixels }\end{array}$ & $\begin{array}{l}\text { It is more efficient for the } \\
\text { noise reduction also preserve } \\
\text { the useful information of the } \\
\text { image. }\end{array}$ \\
\hline 2012 & Jaspreet Kaur & $\begin{array}{l}\text { Fuzzy logic with } \\
\text { adoptive filtering }\end{array}$ & $\begin{array}{l}\text { Reduction is done by Histogram } \\
\text { Method. }\end{array}$ & Performs optimise result. \\
\hline 2013 & $\begin{array}{l}\text { M. González-Hidalgo, } \\
\text { S. Massanet }\end{array}$ & $\begin{array}{l}\text { Fuzzy mathematical } \\
\text { morphology }\end{array}$ & $\begin{array}{l}\text { Detection is done by fuzzy tophat } \\
\text { transforms \& reduction by T-norm } \\
\text { and mathematical morphing. }\end{array}$ & $\begin{array}{l}\text { Perform better result than } \\
\text { that of DBA, SMF3, SMF5, } \\
\text { AMF9 ,AMF17. }\end{array}$ \\
\hline 2013 & $\begin{array}{l}\text { S. Athi Narayanan, G. } \\
\text { Arumugam, Prof. } \\
\text { Kamal Bijlani }\end{array}$ & Trimmed Median Filter & $\begin{array}{l}\text { Iteration based adoptive trimmed } \\
\text { median filtering along with } \\
\text { adoptive window trimmed filtering }\end{array}$ & $\begin{array}{l}\text { This filtering technique } \\
\text { provide better result than } \\
\text { mean, median AWMF. }\end{array}$ \\
\hline 2013 & Firas Ajil Jassim & $\begin{array}{l}\text { Kriging } \\
\text { filtering }\end{array}$ & $\begin{array}{l}\text { Passes through two phases one is } \\
\text { sequential search with prediction, } \\
\text { then replacing the noisy pixel by } \\
\text { interpolation values. }\end{array}$ & $\begin{array}{l}\text { Preserves edges and } \\
\text { blurring. }\end{array}$ \\
\hline 2013 & $\begin{array}{l}\text { Abhishek R , Srinivas } \\
\mathrm{N}\end{array}$ & $\begin{array}{l}\text { weighted } \\
\text { filter(WMF) }\end{array}$ & $\begin{array}{l}\text { First noisy pixels are detected } \\
\text { then they are replaced with Central } \\
\text { noise-free mean value ordered. }\end{array}$ & $\begin{array}{l}\text { Effective for high density } \\
\text { impulses noise removal also } \\
\text { Preserver edges } \\
\text { cannotdamage in the image } \\
\text { while effectively suppressing } \\
\text { salt and pepper noise. }\end{array}$ \\
\hline 2013 & $\begin{array}{l}\text { YueyangLi, } \\
\text { HaichiLuo }\end{array}$ & $\begin{array}{l}\text { neuro- } \\
\text { fuzzy(NF)network } \\
\text { impulse noise filter }\end{array}$ & $\begin{array}{l}\text { Two NF filter are there. Each NF } \\
\text { filter has } 4 \text { inputs and } 1 \text { output } \\
\text { which evaluates ratio b/w all pixels } \\
\text { in a data window and } 3 \text { appropriate } \\
\text { pixels in filtering window. }\end{array}$ & $\begin{array}{l}\text { Due to Neuro-Fuzzy } \\
\text { Network filter this filter } \\
\text { efficiency is much higher } \\
\text { than that of traditional ones. } \\
\text { This filter get modified } \\
\text { automatically through the } \\
\text { training and iterations. }\end{array}$ \\
\hline 2013 & $\begin{array}{l}\text { Masoumeh } \\
\text { Mahallati, } \\
\text { Ghaderi, } \\
\text { Ghasemi }\end{array}$ & fuzzy filtering & $\begin{array}{l}\text { Noisy pixel is replaced by the pixel } \\
\text { which has maximum membership } \\
\text { degree. }\end{array}$ & $\begin{array}{l}\text { Very effective for the higher } \\
\text { noise level. }\end{array}$ \\
\hline 2014 & $\begin{array}{l}\text { Jitender } \\
\text { Abhilasha }\end{array}$ & $\begin{array}{l}\text { Iterative } \\
\text { Unsymmetrical } \\
\text { Trimmed Midpoint- } \\
\text { Median Filter }\end{array}$ & $\begin{array}{l}2 \text { steps } \\
1^{\text {st proposed median filter is }} \\
\text { applied iteratively } 2 \text { times in the } \\
\text { noisy pixels then Modified } \\
\text { Decision based Mean Median Filter } \\
\text { (MDBMMF) is applied to the } \\
\text { output. }\end{array}$ & $\begin{array}{l}\text { Gives the better performance } \\
\text { than. } \\
\text { MDBMMF }\end{array}$ \\
\hline 2014 & $\begin{array}{l}\text { Sukhwinder Singh, Dr. } \\
\text { Neelam Rup Prakash }\end{array}$ & $\begin{array}{l}\text { modified } \\
\text { median filter }\end{array}$ & $\begin{array}{l}\text { First detect the noise then adaptive } \\
\text { window filtering technique is } \\
\text { applied to reduce the noise. }\end{array}$ & $\begin{array}{l}\text { Better than other standard } \\
\text { filters at all noise densities. }\end{array}$ \\
\hline 2014 & $\begin{array}{l}\text { Tian Bai a,b,n, } \\
\text { JieqingTan a, MinHua, } \\
\text { YanWang }\end{array}$ & $\begin{array}{l}\text { continued } \\
\text { interpolation } \\
(\mathrm{CFIF})\end{array}$ & $\begin{array}{l}\text { Two step process, where in } \\
\text { First step uncorrupted pixels are } \\
\text { left unchanged, taking corrupted } \\
\text { pixel as centre value for direction } \\
\text { continued fractions interpolation is } \\
\text { calculated for the noisy image. }\end{array}$ & $\begin{array}{l}\text { Preserve edges while } \\
\text { removing noise. }\end{array}$ \\
\hline 2014 & Sema Koc Kayhan & $\begin{array}{l}\text { 2-stage impulse noise } \\
\text { removal system }\end{array}$ & $\begin{array}{l}\text { A neuro-fuzzy based impulse } \\
\text { noise detector (NFIDET) is used to }\end{array}$ & $\begin{array}{l}\text { Gives the } \\
\text { performance. }\end{array}$ \\
\hline
\end{tabular}




\begin{tabular}{|c|c|c|c|c|}
\hline & Author & Method & Characteristic & Advantage \\
\hline 2014 & $\begin{array}{l}\text { U. Sahin ,S. Uguz, F. } \\
\text { Sahin }\end{array}$ & fuzzy-cellular automata & $\begin{array}{l}\text { detect the noisy pixel then } \\
\text { An adaptive robust weighted mean } \\
\text { (ARWM) filter is used to remove } \\
\text { the noisy pixel. } \\
\text { Local fuzzy transition rule is } \\
\text { applied which gives a membership } \\
\text { Value to the corrupted pixel } \\
\text { neighbourhood and assigns next } \\
\text { state value as a central pixel value. }\end{array}$ & $\begin{array}{l}\text { Reduce the noise effectively } \\
\text { even a higher level of the } \\
\text { noise. }\end{array}$ \\
\hline 2015 & $\begin{array}{l}\text { Shubhendu Banerjee, } \\
\text { Aritra } \\
\text { Bandyopadhyay, Rajib } \\
\text { Bag, Atanu Das }\end{array}$ & iterative method & $\begin{array}{l}\text { First the image is dived into four } \\
\text { equal segments, then foe each } \\
\text { segment cross the middle and } \\
\text { different pixel approximation } \\
\text { (averaging) method is applied. } \\
\text { Then above step is iterated a } \\
\text { number of times until a desired } \\
\text { result is found. }\end{array}$ & $\begin{array}{l}\text { Successful in achieving } \\
\text { accountable value of result } \\
\text { for } 40 \% \text { to } 80 \% \text { level of } \\
\text { noise. }\end{array}$ \\
\hline
\end{tabular}

\section{Results}

\subsection{Evaluation criteria}

The parameters which are used for the performance evolution are peak signal to noise ratio (PSNR), signal to noise ratio (SNR), mean square error (MSE), normalised absolute error (NAE), average difference (AD), structural content (SC), and maximum difference (MD).

\section{2performance evaluation}

Table 3 Noise density 20\% test image: Lena

\begin{tabular}{llllllll}
\hline Type of Filter & PSNR & SNR & MSE & NAE & AD & SC & MD \\
\hline Trimmed filter & 25.6675 & 47.3338 & 179.9437 & 0.048 & 0.6481 & 1 & 212 \\
Trim mean & 23.3719 & 44.7056 & 299.1516 & 0.0879 & 1.1738 & 1 & 129 \\
median & 26.7834 & 52.0189 & 136.3753 & 0.0351 & 0.2215 & 1 & 220 \\
mean & 20.3467 & 57.42 & 600.3582 & 0.1492 & 0.0630 & 1 & 143 \\
Gaussian & 16.1016 & 51.9012 & 1595.6 & 0.1789 & 0.2323 & 0.9636 & 198 \\
\hline
\end{tabular}

\section{Discussion}

We perform the result on the original lena.jpg image. Performance of the different filtering techniques to reduce the salt and pepper noise is shown in the table. From the above table we conclude that the median filter gives the better performance to reduce the salt and pepper noise compare to the other filtering technique.

\section{Conclusion and future works}

In digital image processing noise reduction is the essential step. Noise reduction refers to the removing the unwanted things from the image to get the better quality of the image. This paper reviews various filtering technique to remove the salt and pepper noise. Salt and pepper noise is generally introduced in the image during the image acquisition. This type
This section describes the performance of different filtering techniques to reduce the salt and pepper noises are evaluated. We take the Lena image as a test image in ".jpg" format as an original image. The image is corrupted by the salt \& pepper noise with $20 \%$ noise density. De-noising the image using different filters and their performance comparison are carried out which is shown in the Table 3. 


\section{References}

[1] Verma R, Ali DJ. A comparative study of various types of image noise and efficient noise removal techniques. International Journal of Advanced Research in Computer Science and Software Engineering. 2013; 3(10):617-22.

[2] Maity A, Pattanaik A, Sagnika S, Pani S. A comparative study on approaches to speckle noise reduction in images. In international conference on computational intelligence and networks 2015 (pp. 148-55). IEEE.

[3] Chen T, Wu HR. Adaptive impulse detection using center-weighted median filters. IEEE Signal Processing Letters. 2001; 8(1):1-3.

[4] Turkmen I. Efficient impulse noise detection method with ANFIS for accurate image restoration. AEUInternational Journal of Electronics and Communications. 2011; 65(2):132-9.

[5] Mythili C, Kavitha V. Efficient technique for color image noise reduction. The Research Bulletin of Jordan, ACM. 2011; 1(11):41-4.

[6] Hwang H, Haddad RA. Adaptive median filters: new algorithms and results. IEEE Transactions on Image Processing. 1995; 4(4):499-502.

[7] Padmasini N, Abbirame KS, Yacin SM, Umamaheswari R. Speckle noise reduction in spectral domain optical coherence tomography retinal images using anisotropic diffusion filtering. In International Conference on Science Engineering and Management Research 2014 (pp. 1-5). IEEE.

[8] Kahdum AI. Image steganalysis using image quality metrics (Structural Contents Metric). IBN ALHaitham Journal for Pure and Applied Science. 2017; 21(4):24-31.

[9] Talukder MH, Islam MA, Ghosh TK, Rahman MM. A new filtering technique for reducing speckle noise from ultrasound images. International Journal of Research in Computer and Communication Technology. 2013; 2(9):685-8.

[10] Narayanan SA, Arumugam G, Bijlani K. Trimmed median filters for salt and pepper noise removal. International Journal of Emerging Trends \& Technology in Computer Science. 2013; 2(1):35-40.

[11] Mahallati MM, Ghaderi R, Ghasemi J. Impulse noise reduction using fuzzy based approach. In Iranian conference on fuzzy systems 2013 (pp. 1-4). IEEE.

[12] González-Hidalgo M, Massanet S, Mir A, RuizAguilera D. High-density impulse noise removal using fuzzy mathematical morphology. In conference of the European society for fuzzy logic and technology 2013. Atlantis Press.

[13] Singh S, Prakash DN. Modified adaptive median filter for salt \& pepper noise. International Journal of Advanced Research in Computer and Communication Engineering 2014:5067-72.

[14] Chan RH, Ho CW, Nikolova M. Salt-and-pepper noise removal by median-type noise detectors and detailpreserving regularization. IEEE Transactions on Image Processing. 2005; 14(10):1479-85.
[15] Koli M, Balaji S. Literature survey on impulse noise reduction. Signal \& Image Processing. 2013; 4(5):7595.

[16] Kaisar S, Mahmud JA. Salt and pepper noise detection and removal by tolerance based selective arithmetic mean filtering technique for image restoration. International Journal of Computer Science and Network Security. 2008; 8(6):309-13.

[17] Al-Khaffaf HS, Talib AZ, Salam RA. Removing saltand-pepper noise from binary images of engineering drawings. In international conference on pattern recognition 2008 (pp. 1-4). IEEE.

[18] Gebreyohannes T, Kim DY. Adaptive noise reduction scheme for salt and pepper. arXiv preprint arXiv:1201.2050. 2012.

[19] Kaur J. Salt \& pepper noise removal using fuzzy based adaptive filter. International Journal of Science, Engineering and Technology Research. 2012; 1(5):246.

[20] Hsu CY, Tsui TS, Yu SS, Tseng KK. Salt and pepper noise reduction by cellular automata. International Journal of Applied Science and Engineering. 2011; 9(3):143-60.

[21] Bansal EH, Kaushik EG. Detection and reduction of impulse noise using noise adaptive fuzzy switching median filter. International Journal of Advanced Engineering Technology. 2011; 2(3):237-9.

[22] Babu KR, Rahul LA, Souri PV, Suneetha A. Image denoising in the presense of high level salt and pepper noise using modified median filter. IJCST.2011; 2(1):180-3.

[23] Siddavatam R, Sood A, Syamala Jayasree P, Ghrera SP. An intelligent recursive algorithm for $95 \%$ impulse noise removal in grayscale and binary images using lifting scheme. In Proceedings of the World Congress on Engineering and Computer Science 2011.

[24] Li Y, Sun J, Luo H. A neuro-fuzzy network based impulse noise filtering for gray scale images. Neurocomputing. 2014; 127:190-9.

[25] Kumar J, Abhilasha. An iterative unsymmetrical trimmed midpoint-median filter for removal of high density salt and pepper noise. International Journal of Research in Engineering and Technology. 2014; 3:4450.

[26] Bai T, Tan J, Hu M, Wang Y. A novel algorithm for removal of salt and pepper noise using continued fractions interpolation. Signal Processing. 2014; 102:247-55.

[27] Kayhan SK. An effective 2-stage method for removing impulse noise in images. Journal of Visual Communication and Image Representation. 2014; 25(2):478-86.

[28] Sahin U, Uguz S, Sahin F. Salt and pepper noise filtering with fuzzy-cellular automata. Computers \& Electrical Engineering. 2014; 40(1):59-69.

[29] Banerjee S, Bandyopadhyay A, Bag R, Das A. Moderate density salt \& pepper noise removal. International Journal of Electronics \& Communication Technology. 2015; 6(1):44-8. 
ACCENTS Transactions on Image Processing and Computer Vision, Vol 4(10)

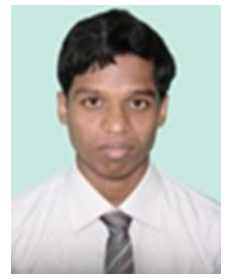

Alenrex Maity had completed his B.TECH from Institute of Technology and Marine Engineering, Diamond Harbour, Kolkata, WB in 2012 in the Department of Computer Science \& Engineering. He completed his M.Tech in the Department of Computer Science \& Engineering from KIIT University,

Bhubaneswar, Odisha. His research areas are Image processing and Soft Computing.

Email:alenrex8@gmail.com

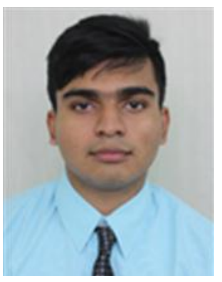

Rishav Chatterjee is an Undergraduate student of the Department of Computer Science Engineering, KIIT (Deemed to be University). $\mathrm{He}$ is an aspiring junior researcher who has worked on various fields of Machine Learning, Image Processing and Cryptography. He has published papers in some reputed conferences like SOCPROS, CINE and IEMIS etc. His main research areas consist of Blockchains and Image Processing.

Email: rishavpiku@gmail.com 